\title{
Contraceptive use in women with inherited metabolic disorders: a retrospective study and literature review
}

\author{
Jessica I. Gold ${ }^{1 *}$ (B), Nina B. Gold², Diva D. DeLeon ${ }^{3,4}$ and Rebecca Ganetzky 4,5
}

\begin{abstract}
Background: Reproductive planning is an emerging concern for women with inherited metabolic disease (IMD). Anticipatory guidance on contraception is necessary to prevent unintended pregnancies in this population. Few resources exist to aid informed decision-making on contraceptive choice. A retrospective case-control study was performed to examine trends in reproductive planning for adolescent and adult women seen at the Children's Hospital of Philadelphia (CHOP). Literature review on contraception and IMD was performed to assess global use.

Results: In a cohort of 221 reproductive-aged female IMD patients, 29.4\% reported routine contraceptive use. Anticipatory guidance on contraception was provided by metabolic physicians to $36.8 \%$ of patients during the study period. Contraception discussion was more likely to occur in women older than 21 years, who lived independently and were followed by gynecology. Women who received contraception counseling from their metabolic physician were 40 -fold more likely to use regular contraception. Use of combined hormonal contraceptives was most commonly reported, but contraception choice varied by age and IMD.
\end{abstract}

Conclusion: Metabolic physicians are ideally suited to provide guidance on contraception to women with IMD. Reproductive planning should be addressed routinely using shared decision-making. Contraceptives should be selected for their efficacy, effects on metabolism, and likelihood of patient adherence.

Keywords: Contraception, Reproductive planning, Adult metabolic medicine, Inherited metabolic disorders, Pregnancy, Birth control

\section{Background}

Due to expanded newborn screening and medical advancements in care and diagnosis, people with inherited metabolic disorders (IMD) are surviving into adulthood with improved health. As these individuals age, there is a growing need for counseling on reproductive care $[1,2]$. For many women with IMD, pregnancy carries risks both to the patient and to the developing

\footnotetext{
*Correspondence: goldj@email.chop.edu

${ }^{1}$ Division of Human Genetics, Section of Biochemical Genetics, The

Children's Hospital of Philadelphia, 3401 Civic Center Blvd, Philadelphia, PA 19104, USA

Full list of author information is available at the end of the article
}

fetus, particularly if the pregnancy is unintended and the underlying IMD is inadequately managed. Some hormonal contraceptives may disrupt metabolism, leading to adverse outcomes. As such, counseling on contraceptive selection is important for women with IMD. Because patients with IMD often have long-lasting and frequent contact with their metabolic physicians, these clinicians are well-positioned to facilitate anticipatory guidance discussions on reproductive care.

The World Health Organization (WHO) has published guidelines for contraception in the setting of common medical disorders, including liver disease, hypertension, and diabetes. No centralized information on best practices for women with rare diseases, including IMD, exists. 
Contraceptives vary widely in their efficacy, mechanism of action, usage, and side effects. For women with medical comorbidities, it is critical to balance the risks of any contraceptive method with the adverse outcome of an unintended pregnancy $[3,4]$. This study and review of the literature aims to examine trends in reproductive planning for women with IMD at one center and propose considerations for counseling on contraceptive selection.

\section{Results}

The Metabolism section at CHOP followed 221 reproductive-aged females, including 111 adolescents $12-21$ years old, and 110 adults $22-50$ years old between January 2012 and December 2019. Most adolescent patients live with a parent or caregiver (93\%), while half of the adult patients live independently (50.9\%). Intellectual disability (ID) has been diagnosed in $37.1 \%$ of our cohort, affecting $41.4 \%$ of adolescents and $32.7 \%$ of adults.

A metabolic physician documented counseling about contraception use during at least one visit with $36.8 \%$ of reproductive-aged patients. Discussions were significantly more likely to occur with patients who were adults (OR 3.3, CI 1.9-5.9), live independently (OR 3.1, CI 1.7-5.7), or are followed by gynecologists (OR 5.93, CI 3.24-10.8) (Fig. 1). The presence of ID did not significantly affect introduction of this topic. Routine contraceptive use was reported by $29.4 \%$ of patients, including $20.7 \%$ of adolescents and $38.9 \%$ of adults (Fig. 1). Contraception use was significantly higher in adult patients (OR 2.6, CI 1.4-4.6), patients living independently (OR 4.23, CI 2.3-7.9), and patients seeing gynecologists (OR 3.43, CI 1.88-6.26). Most notably, contraceptive use was 40-fold more likely in patients who received anticipatory guidance from their metabolic provider. Counseling on contraception by a metabolic physician led to initiation of use within $2.37 \pm 1.3$ visits.

Combined hormonal contraceptives $(\mathrm{CHC})$, including the pill, patch, and vaginal ring were most commonly used (Fig. 2A). Long-acting reversible contraception (LARC), including reversible forms (IUD or progesterone implant) and surgical methods, was more likely to

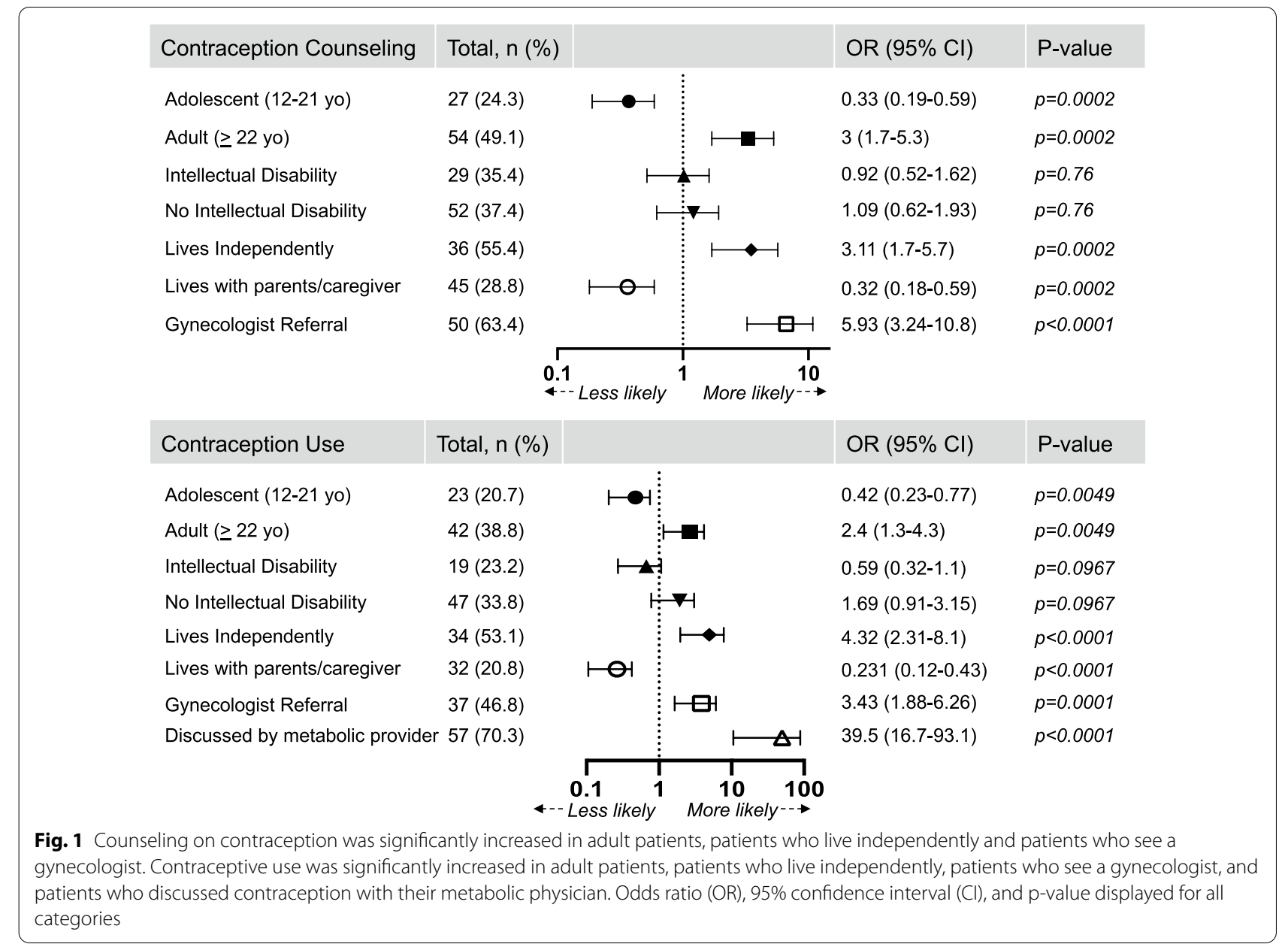



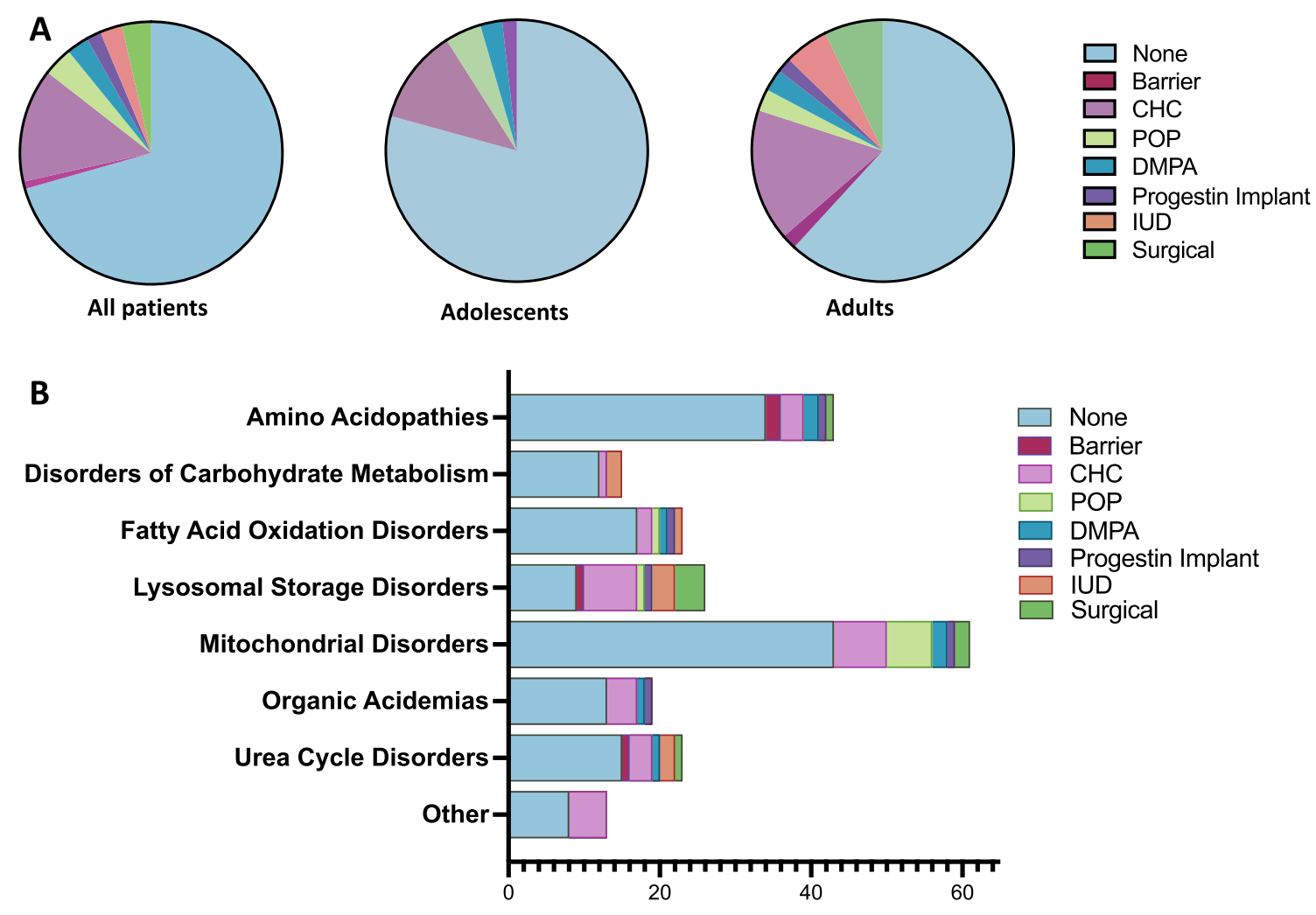

Number of Patients

Fig. 2 Contraceptive method varies by age and IMD. A Current documented contraceptive method in all reproductive-aged women followed by the CHOP metabolism clinic ( $n=221$, left), adolescent women $(n=111$, middle), and adult $(n=110$, right). B Current and historical contraception use according to IMD diagnosis. CHC combined hormonal contraception; POP progestin-only pills; IUD intrauterine device

be used by adults compared to adolescents (OR 6.46, CI 1.33-31.3). We also examined use of contraception according to underlying metabolic diagnosis (Fig. 2B). Current and historic forms of contraception were included. Contraception use varied among IMD class. Patients with lysosomal storage disorders, specifically Gaucher disease, were most likely to use contraception, with the majority opting for $\mathrm{CHCs}$ or surgical methods. Of note, no patient in our cohort with homocystinuria or a hepatic glycogen storage disorder (GSD) had ever used a $\mathrm{CHC}$, which is contraindicated in these disorders [5-7].

Many patients at high risk for adverse events during pregnancy were not using contraception. Most patients with urea cycle disorders (UCD) and organic acidemias did not report contraception use $(65 \%$ and $68 \%$ respectively). Among patients with phenylketonuria (PKU), $77 \%$ had no contraceptive use ever documented, despite consensus recommendations [8]. Anticipatory guidance regarding pregnancy and PKU was not universally provided. Discussion on the risks of uncontrolled PKU in pregnancy only occurred for $30 \%$ of adolescent patients and $66.7 \%$ of adult patients. Only $25 \%$ of patients on pegvaliase and $40 \%$ of patients on eliglustat reported contraceptive use, despite it being a prerequisite for these medications.

\section{Literature review}

Review of literature on IMD and contraception primarily revealed case reports. There is no comprehensive resource on contraceptive use, efficacy, or adverse events in IMD. Guidelines on homocystinuria, GSD I and III, and Wilson disease provided the most specific recommendations. Estrogen-containing contraception is contraindicated in homocystinuria due to the risk of thrombosis and stroke [9]. Estrogen-containing contraceptives are also discouraged in hepatic GSD due to their connection to the formation and growth of hepatic adenomas [7, 10, 11]. Ethinyl estradiol may increase triglycerides, a concern in hepatic GSD, and familial hyperlipidemias [7, 11, 12]. Copper-containing IUDs are discouraged in Wilson disease due to theoretical copper absorption. International guidelines on PKU encouraged contraceptive use without providing a preferred methods $[8,13-15]$. We compiled contraception 
Table 1 Studies addressing contraceptive use in IMD

Disorder

Galactosemia

Gaucher Disease

Glycogen Storage Disease I

Glycogen Storage Disease Ib

Glycogen Storage Disease III

Familial Hypercholesterolemia

Hereditary Hemochromatosis

Methylmalonic Acidemia/Propionic Acidemia

Niemann Pick C

Phenylketonuria

Wilson's disease

\section{Recommendation}

Avoid estrogen-containing contraception due to increased risk of thrombosis

Counsel about adequate birth control methods as hormonal methods of cycle control may fail to prevent pregnancy in women with elevated FSH. IUD may provide the lowest failure rate

Counsel patients that they have reduced fertility, not complete infertility

All oral contraceptive pills (OCP and POP) contain lactose as binding agents, recommend alternative methods

No known contraindications for $\mathrm{CHC}$ or progesterone-only contraception unless there is severe liver involvement

Avoid copper IUDs if patient is at risk for menorrhagia

Contraception must be used by both men and women who are receiving Miglustat

Avoid ethinylestradiol due to the link with hepatic adenomas. Recommend POP

Progestin-only contraceptives may have risks of reduced bone mineral density

Avoid use of IUDs due to potential risk of increased infection

Avoid estrogen-containing contraception due to risk of hepatic adenomas. If using progesteroneonly contraceptive, monitor for reduced bone mineral density

Recommend low estrogen-containing oral contraceptives, IUD, and barrier techniques. For women older than 35 years, IUDs and barrier techniques are preferred

Counsel on contraception prior to starting statin with reinforcement provided annually

Use shared decision-making if menstrual suppression is indicated due to potential risk of elevated ferritin and need for phlebotomy

There are no known contraindications for the use of hormonal contraception. Discuss contraception and sexual health during adolescence

Contraception must be used by both men and women who are receiving Miglustat

Recommend the most effective form of contraceptive

Prior to conception, continue contraception until phenylalanine levels are within target range for at least 2 weeks

Begin age-related sexual education and guidance on risk for maternal PKU syndrome at age 12

Develop a robust transition program so that young adult women are not lost to follow-up

Avoid estrogen-containing contraception and copper IUD. Recommend progesterone-only contraception, barrier methods, and spermicides

\section{References}

Morris et al. [5]

Welling et al. [34]

van Erven et al. [34]

Granovsky-Grisaru et al. [35], Granovsky-Grisaru et al. [36]

Granovsky-Grisaru et al. [36]

Cox et al. [37]

Mairovitz et al. [6], Sechi et al. [7]

Kishani et al. [11]

Kishani et al. [11]

Kishani et al. [38]

Balla et al. [12], Watts et al. [39]

Balla et al. [12], Watts et al. [39]

Kalinowski et al. [40]

Baumgartner et al. [14]

Wraith et al. [41]

van Wegberg et al. [8], AAP [15]

van Wegberg et al. [8], van Spronsen et al. [42]

van Wegberg et al. [8], AAP [15], Camp et al. [43]

van Wegberg et al. [8]

Connolly et al. [44], Haimov-Kochman et al. [45]; EASL [46], Kathawala [47], Patil et al. [48]

CHC combined hormonal contraception; IUD intrauterine device; OCP oral contraceptive pills; $P K U$ phenylketonuria; $P O P$ progestin-only pills 
recommendations for specific IMDs based on the literature reviewed (Table 1).

\section{Discussion}

Reproductive health planning is an emerging, crucial issue for people with IMDs. Contraception limits risks to patients with IMD and their offspring, as it allows for adequate reproductive planning and early pregnancy monitoring. Contraception is therefore a necessary component of the healthcare of adults and adolescents with IMD.

Contraception counseling was most likely to occur with adult women who live independently. These women are likely to attend visits independently or with a partner, avoiding the potential discomfort of addressing sexual health in front of parents or caregivers. Adult women living independently may demonstrate higher career focus making them more likely to use contraception to delay pregnancy [16]. Gynecology referral had a positive impact on contraceptive use. LARC have the lowest failure rate and were used significantly more frequently in females followed by gynecologists (with gynecology: 9/81; without gynecology: 4/121, p < 0.04). Joint management with gynecology allows for a greater range of contraceptive options.

Diagnosis of ID had an equivocal effect on both contraception counseling and use of contraception. This runs counter to current literature on sexual health in women with ID, where the presence of ID decreases the likelihood of reproductive planning [17]. Metabolic physicians may be uniquely suited to have such conversations with patients with ID because of strong rapport with patients and their families due to longstanding relationships. For our cohort with ID, there was no significant benefit of gynecology consultation on contraceptive use (OR 2.45, CI 0.86-6.96, $\mathrm{p}=0.092$ ). In contrast, metabolic physician-led counseling on contraception significantly improves actual usage among women with ID and IMD (OR 4.8, CI 1.46-15.8, $\mathrm{p}=0.01$ ) Most women with ID in our cohort opted for daily oral contraception, such as POP or OCP $(73 \%)$, and only one patient chose a LARC (IUD). We speculate that these women are already taking several daily medications and, therefore, are not burdened by adding additional daily oral medications. It is also possible that there is insufficient awareness about LARC in this population or limited options for placement.

For all cohorts, metabolic physicians are well-poised to initiate conversations about reproductive health. In our clinic, engaging women even once about reproductive planning led to a 40-fold increase in contraceptive use (Fig. 1). Patients were more likely to initiate contraception on the advice of their metabolic physician compared to their gynecologist. In our clinical experience, patients with IMD frequently defer to their metabolic physician for advice on any new medication or supplement. This highlights the critical role that the metabolic physician plays in encouraging contraception.

Unfortunately, overall, contraceptives were used only by a minority of patients across all classes of IMD, increasing the risk for unintended pregnancy (Fig. 2). This was true even in conditions where pregnancy was associated with high risk for adverse pregnancy outcomes. Only $23 \%$ of women with PKU have ever used contraception, with slightly higher percentages for female patients with organic acidemias (32\%) and UCDs (35\%). This resulted in an unacceptably high rate of maternal PKU syndrome (1/12 pregnancies), which causes irreversible neurologic damage to the fetus. These data are similar to those found in other studies showing that reproductive health is often omitted from healthcare transition planning [18]. In general, women with chronic diseases are less likely to use contraception, despite the risks of unintended pregnancy $[19,20]$. While IMD-related comorbidities may preclude reproduction for some, many women with IMD are sexually active and should be receive anticipatory guidance on contraception.

One barrier to universal metabolic counseling on contraception is the lack of systematic resources. In the IMD literature, most recommendations are provided on an ad hoc, case report basis. Contraception was addressed in $14.3 \%(12 / 84)$ of clinical practice guidelines (Table 2). The lack of expert opinion minimizes the importance of reproductive health counseling and fails to provide guidance for metabolic physicians. Misperceptions may exist about sexual activity in patients with IMD, especially those that are evaluated in a pediatric context or who still live with a caregiver, and providers may feel discomfort discussing this topic with patients whom they have known since childhood [21]. Counseling through educational hand-outs or inclusion of questionnaires in the electronic health record could lead to uniform guidance on contraception. Likewise, incorporation of healthcare contracts may encourage contraceptive use prior to starting potentially teratogenic medications, such as pegvaliase. Similar processes, for example the iPledge program for isoretinol use, have shown efficacy in preventing unintended pregnancy in analogous contexts [22].

This study is limited by the setting of our cohort. CHOP is a stand-alone children's hospital. It is not affiliated with an adult hospital. The Section of Metabolic Disease at CHOP follows all-aged patients (currently newborn to 88 years-old). Adults with disorders of intermediary metabolism continue to be admitted to $\mathrm{CHOP}$ for metabolic crises and other emergent care. There are six attending physicians within the section, all of whom 
Table 2 Sex hormone effects on metabolism

\begin{tabular}{|c|c|c|c|}
\hline Hormone & Effect on metabolism & Example affected conditions & Author \\
\hline \multirow[t]{5}{*}{ Estrogen } & $\begin{array}{l}\text { Increases total cholesterol, triglycerides, } \\
\text { and high-density lipoproteins, decreases } \\
\text { low-density lipoproteins }\end{array}$ & $\begin{array}{l}\text { Cholesterol biosynthesis disorders, Cho- } \\
\text { lesterol storage disorders, GSD }\end{array}$ & $\begin{array}{l}\text { Winkler et al. [48], Nash et al. [49], Ruoppolo } \\
\text { et al. [50] }\end{array}$ \\
\hline & Increases circulating glucose and insulin & $\begin{array}{l}\text { FAOD, GSD, disorders with risk of hypo- } \\
\text { glycemia }\end{array}$ & Winkler et al. [48], Godsland et al. [51] \\
\hline & $\begin{array}{l}\text { Decreases muscle glucose uptake via } \\
\text { repression of GLUT4 expression }\end{array}$ & Muscle-predominant GSD & Barros et al. [52] \\
\hline & $\begin{array}{l}\text { Decreased absorption of B vitamins, } \\
\text { specifically riboflavin, thiamine, and } \\
\text { pyridoxine }\end{array}$ & PDH deficiency, Homocystinuria & $\begin{array}{l}\text { Anderson et al. [53], Webb et al. [54], Rose } \\
\text { et al. [55] }\end{array}$ \\
\hline & $\begin{array}{l}\text { Increased risk of venous thromboembo- } \\
\text { lism }\end{array}$ & Homocystinuria, Cobalaminopathies & Den Heijer et al. [23] \\
\hline \multirow[t]{2}{*}{ Progestins } & $\begin{array}{l}\text { Increase triglycerides and high-density } \\
\text { lipoproteins, decreases low-density } \\
\text { lipoprotein }\end{array}$ & $\begin{array}{l}\text { Cholesterol biosynthesis disorders, Cho- } \\
\text { lesterol storage disorders, GSD }\end{array}$ & Godsland et al. [51], Butler et al. [56] \\
\hline & $\begin{array}{l}\text { Decrease bone mineral density with } \\
\text { DMPA }\end{array}$ & Disorders with risk for poor bone health & ACOG [4] \\
\hline \multirow[t]{6}{*}{$\begin{array}{l}\text { Combined } \\
\text { estrogen and } \\
\text { progestin }\end{array}$} & $\begin{array}{l}\text { Changes in plasma amino acid profiles: } \\
\text { decreases glutamine, glycine, proline, } \\
\text { lysine, hydroxyproline, ornithine, tyrosine } \\
\text { and increases isoleucine and phenylala- } \\
\text { nine }\end{array}$ & $\begin{array}{l}\text { PKU, IVA, GAMT deficiency, Lysinuric } \\
\text { Protein Intolerance }\end{array}$ & Ruoppolo et al. [50], Wang et al. [57] \\
\hline & $\begin{array}{l}\text { Increase total cholesterol, triglycerides, } \\
\text { and high-density lipoproteins }\end{array}$ & $\begin{array}{l}\text { Cholesterol biosynthesis disorders, Cho- } \\
\text { lesterol storage disorders, GSD }\end{array}$ & Wang et al. [57] \\
\hline & Decrease free and total carnitine & $\begin{array}{l}\text { Carnitine Uptake deficiency, Secondary } \\
\text { carnitine deficiency }\end{array}$ & Bach et al. [58] \\
\hline & Increase cholic acid & Disorders of bile acid metabolism & Connolly et al. [44] \\
\hline & Decrease chenodeoxycholic acid & Cerebrotendinous Xanthomatosis & Connolly et al. [44] \\
\hline & Increase ceruloplasmin & Wilson disease & Roberts et al. [59] \\
\hline
\end{tabular}

GSD glycogen storage disease; FAOD fatty acid oxidation disorders; $P D H$ pyruvate dehydrogenase; $P K U$ phenylketonuria, IVA isovaleric acidemia; GAMT guanidinoacetate methyltransferase

are trained in pediatrics and clinical genetics. Adults are frequently seen by their childhood metabolic physician. Potential barriers include lack of experience in discussing or providing contraception, limited knowledge on contraceptive options, scant training on offering adult-centered care, and discomfort with shared decision-making. Our cohort, with only $30 \%$ contraceptive use, may not be generalizable to metabolism clinics specifically dedicated to adult-centered care. Metabolic physicians with training in internal medicine, family medicine, or obstetricsgynecology have a stronger background in discussing and prescribing contraception, leading to higher rates of compliance with contraceptives.

Another possibility is that reproductive healthcare is lacking throughout the practice of metabolism. Many IMD were previously thought to be life-limiting with accompanying decrease in reproductive fitness. The advent of newborn screen, novel therapeutics, and improved care created a new population of adults who require specialized management. Women with IMD require more uniformity in counseling on the adverse effects of unintended pregnancy and how contraception can ameliorate these risks. Metabolic physicians can serve as leaders in this area, working cooperatively with gynecology or primary care providers to best support patients' decision-making. To empower metabolism-driven discussion of contraception, we summarize important aspects of counseling on contraception for women with IMD below.

\section{Contraceptive counseling for women with IMD}

To provide optimal reproductive planning advice to women with IMD, both the efficacy of the method and the effects of sex hormones on metabolism should be considered. The WHO recommends using the contraceptive with the lowest failure rate in women with health risks due to unintended pregnancy (currently LARC, including the hormonal and non-hormonal IUD and the progestin implant) [3, 4]. Estrogen and progestin, both separately and combined as $\mathrm{CHC}$ are responsible for several changes to metabolism in healthy women (Table 2). Patients' PCPs or gynecologists may not consider the side effects of contraception on metabolic pathways, placing 
the metabolic physician in a unique role to suggest the method most compatible with the patient's diagnosis.

IMD patients' comorbidities also play an important role in contraceptive choice. Use of $\mathrm{CHC}$ is contraindicated in women with a history of hypertension, cardiac disease, or stroke (21.5\% of our patient cohort) [3, 4]. Migraines with aura, a common manifestation of mitochondrial disease and reported in $23.1 \%$ of our entire cohort, are another contraindication for $\mathrm{CHC}$ use due to the risk of stroke [12]. Women with a history or increased risk for venous thromboembolism due to homocystinuria, cobalaminopathies and other thrombophilic IMDs also should not receive $\mathrm{CHC}[23,24]$. Women with IMD may be the recipients of solid organ transplants, including liver and kidney. Most contraceptive methods are safe to use after uncomplicated organ transplant, but $\mathrm{CHC}$ are contraindicated in women with acute or chronic graft rejection [3,25]. IUD have also been proven to be safe post-transplant, with no increased risk of developing pelvic infections [26]. Depot medroxyprogesterone (DMPA) and IUD are preferred for women on anti-epileptic drugs due to potential medication interactions $(29.4 \%$ of our cohort) [3]. Partnering with gynceology may be beneficial for identifying the contraceptive with the safest side effect profile.

Contraception may improve IMD symptoms. The guidelines for propionic acidemia/methylmalonic acidemia recommend hormonal contraception for management of perimenstrual metabolic instability [14]. Several cases of catamenial hyperammonemia in UCDs have been described, which resolved with menstrual suppression using DMPA or CHC [27-29]. Hormonal contraception may also limit perimenstrual aggression in Smith-Lemli-Opitz Syndrome and catamenial porphyria crises in acute intermittent porphyria [30, 31]. In our cohort, 16 patients reported catamenial metabolic decompensations, of which 5 (31\%) utilized hormonal contraception for management.

\section{Discussing reproductive health with IMD patients}

It is important to address surgical methods of contraception or sterilization due to its history with the eugenics movement. The United Nations convention on the rights of persons with disabilities states that "people with disabilities must have access on an equal basis to all forms of sexual and reproductive health care [3]." For women with intellectual disability, supported decision-making should occur with a trusted caregiver who will act in the best interests of the patient. Decision-makers should consider social factors, protection against sexual abuse, and support options through potential pregnancy and parenthood [32]. They should also have valid grounds for desiring sterilization, such as avoidance of grave harm from pregnancy or inability to use a reversible contraceptive. For women with IMD, consideration of the metabolic risks of pregnancy and labor must also be weighed. The popularity and effectiveness of LARCs, including the IUD and the progestin implant, may make sterilization a rarer choice [33].

Finally, genetic counseling should occur at least once with adolescent and adult IMD patients. Counseling should address disease inheritance, recurrence risk, and options for genetic testing during antenatal and prenatal periods. Prospective parents should also be informed that variable expressivity occurs between generations for many IMD, making disease course less predictable in offspring. Additionally, discussions about reproductive health may lead to improved care coordination with patients' primary care and $\mathrm{OB}$ providers. These providers may need education about risks during and after pregnancy related to IMDs. Pediatricians of patients' future offspring should also be involved in care, as they may be directing the initial screening or management of newborn infants.

\section{Conclusion}

Use of contraception to prevent unintended pregnancy and catamenial exacerbation of symptoms is important for women with IMD. In our cohort, contraception counseling by a metabolic physician is the strongest predictive factor for routine contraceptive use. Metabolic providers should utilize their trusted relationships with their patients to broach discussions about reproductive health, Advice on contraceptive choice should consider the contraceptive's effects on metabolism, efficacy, comorbidities, side effects, and patient preference. CHC have the most effects on metabolism and may not be the optimal choice for women with IMD. LARC, such as IUD and progestin-implants, have not been studied extensively in this population, but are likely to be well-tolerated and should be considered first line. Greater collaboration with gynecology may encourage greater diversity in contraceptive options, especially LARC. Overall, the decision regarding contraceptive use is best made on an individual basis in concert between the adolescent or adult IMD patient and her physician.

\section{Patients and methods \\ Patients}

A retrospective chart review was conducted for all female patients with ages between 12-50 years-old followed by the Division of Genetics and Metabolism at Children's Hospital of Philadelphia (CHOP) $(n=256)$. Patients with at least two visits with a clinical metabolic physician between January 2012 and December 2019 and a known diagnosis of an IMD (urea cycle disorder, fatty 
acid oxidation disorder, amino acidopathy, lysosomal storage disease, organic acidemia, mitochondrial disorder, glycogen storage disorder) were included. The twovisit criterion was used to ensure that only patients for whom $\mathrm{CHOP}$ was their established metabolic care center were included. We also excluded patients documented to be premenarchal or menopausal during the length of our study period $(\mathrm{n}=35)$. Demographics of our study population meeting inclusion criteria can be found in Table 3.

\section{Statistical analysis}

Logistic regression was used to identify factors associated contraceptive counseling and use. Results were reported as odds ratios (OR) with 95\% confidence intervals. All analyses were conducted using Stata 16.1.

\section{Literature review}

We queried the PubMed and Cochrane Library databases using the following search terms: "inborn error of metabolism \& contraception," "inborn error of metabolism \& contraceptives," "inborn error of metabolism \& birth control" "inborn error of metabolism \& estrogen" "inborn error of metabolism \& progesterone" "inherited metabolic disorder \& contraception," "inherited metabolic disorder \& contraceptives," "inherited metabolic disease \& birth control" "inherited metabolic disorder \& estrogen," and "inherited metabolic disorder \& progesterone." This search identified 31 primary articles. We also examined 84 international clinical practice guidelines on IMD for discussion of contraception.

Table 3 Demographics and clinical characteristics of reproductive-aged female patients meeting inclusion criteria

\begin{tabular}{|c|c|c|c|}
\hline & Total & Adolescents (12-21) & Adults ( $>22)$ \\
\hline Number & 221 & 111 & 110 \\
\hline Age $($ mean $\pm S D)$ & $25.2 \pm 11.3$ & $16.2 \pm 2.6$ & $25.2 \pm 9.3$ \\
\hline \multicolumn{4}{|l|}{ Insurance (n, \%) } \\
\hline Private only & $117(52.9)$ & $59(53.2)$ & $58(52.7)$ \\
\hline Medicare only & $5(2.3)$ & $1(0.9)$ & $4(3.6)$ \\
\hline Medicaid only & $39(17.6)$ & $22(19.8)$ & $17(15.5)$ \\
\hline Self pay only & $1(0.5)$ & $0(0)$ & $1(0.9)$ \\
\hline Private + Medicare & $4(1.8)$ & $1(0.9)$ & $3(2.7)$ \\
\hline Private + Medicaid & $42(19)$ & $26(23.4)$ & $16(14.5)$ \\
\hline Medicaid+Medicare & $12(5.4)$ & $2(1.8)$ & $10(9)$ \\
\hline Private + Medicaid + Medicare & $1(0.5)$ & $0(0)$ & $1(0.9)$ \\
\hline \multicolumn{4}{|l|}{ Race $(n, \%)$} \\
\hline African American & $25(11.3)$ & $12(10.8)$ & $13(11.8)$ \\
\hline Asian & $5(2.3)$ & $3(2.7)$ & $2(1.8)$ \\
\hline Hispanic & $14(6.3)$ & $9(8.1)$ & $5(4.5)$ \\
\hline White & $155(70.1)$ & $69(62.2)$ & $86(78.2)$ \\
\hline Other & $22(10)$ & $18(16.2)$ & $4(3.6)$ \\
\hline \multicolumn{4}{|l|}{ Residence (n, \%) } \\
\hline Lives with parents/caregiver & $154(69.7)$ & $103(92.8)$ & $51(46.3)$ \\
\hline Lives independently & $64(29)$ & $8(7.2)$ & $56(50.9)$ \\
\hline Lives in group home & $3(1.4)$ & $0(0)$ & $3(2.7)$ \\
\hline Intellectual disability (n, \%) & $82(37.1)$ & $46(41.4)$ & $36(32.7)$ \\
\hline \multicolumn{4}{|l|}{ Diagnosis (n, \%) } \\
\hline Aminoacidopathy & $41(18.6)$ & $19(17.1)$ & $22(20)$ \\
\hline Disorder of carbohydrate metabolism & $15(6.8)$ & $11(9.9)$ & $4(3.6)$ \\
\hline Fatty acid oxidation disorder & $21(9.5)$ & $15(13.5)$ & $6(5.5)$ \\
\hline Lysosomal storage disorder & $31(14)$ & $9(8.1)$ & $22(20)$ \\
\hline Mitochondrial disorder & $59(26.7)$ & $28(25.2)$ & $31(28.2)$ \\
\hline Organic acidemia & $22(10)$ & $14(12.6)$ & $8(7.2)$ \\
\hline Urea cycle disorder & $22(10)$ & $7(6.3)$ & $15(13.6)$ \\
\hline Other & $10(4.5)$ & $8(7.2)$ & $2(1.8)$ \\
\hline
\end{tabular}




\section{Abbreviations}

IMD: Inherited metabolic disorders; WHO: World Health Organization; CHOP: Children's Hospital of Philadelphia; ID: Intellectual disability; OR: Odds ratio; Cl: Confidence interval; CHC: Combined hormonal contraception; LARC: Longacting reversible contraception; UCD: Urea cycle disorders; PKU: Phenylketonuria; LSD: Lysosomal storage disorder; DMPA: Depot medroxyprogesterone; IUD: Intrauterine device; OCP: Oral contraception pills; POP: Progestin-only pill; BMD: Bone mineral density; POI: Premature ovarian insufficiency; GSD: Glycogen storage disease; FAOD: Fatty acid oxidation disorder; PDH: Pyruvate dehydrogenase; GAMT: Guanidinoacetate methyltransferase.

\section{Acknowledgements}

Not applicable.

\section{Authors' contributions}

JG conceived the study, participated in study design, data analysis, and drafted the manuscript. She serves as the guarantor for the article. NG participated in data analysis and contributed to writing and revising the manuscript. DD participated in the design of the study and contributed to writing and revising the manuscript. RG participated in study design and contributed to writing and revising the manuscript. All authors read and approved the final manuscript.

\section{Funding}

This work was financially supported by the Sanofi Genzyme/ACMG Foundation Next Generation Fellowship and the NIH T32 GM008638 awarded to Children's Hospital of Philadelphia.

\section{Availability of data and materials}

The datasets analyzed during the current study are available from the corresponding author upon request.

\section{Declarations}

\section{Ethics approval and consent to participate}

The study was approved by the institutional review board of the Children's Hospital of Philadelphia (IRB 20-017227).

\section{Consent for publication}

Not applicable.

\section{Competing interests}

The authors declare no potential conflicts of interest.

\section{Author details}

'Division of Human Genetics, Section of Biochemical Genetics, The Children's Hospital of Philadelphia, 3401 Civic Center Blvd, Philadelphia, PA 19104, USA. ${ }^{2}$ Division of Medical Genetics and Metabolism, Massachusetts General Hospital for Children, Boston, MA, USA. ${ }^{3}$ Division of Endocrinology and Diabetes, The Children's Hospital of Philadelphia, Philadelphia, PA, USA. ${ }^{4}$ Department of Pediatrics, Perelman School of Medicine at the University of Pennsylvania, Philadelphia, PA, USA. 'Division of Human Genetics, Section of Biochemical Genetics, The Children's Hospital of Philadelphia, Philadelphia, PA, USA.

\section{Received: 25 November 2021 Accepted: 30 January 2022}

Published online: 08 February 2022

\section{References}

1. Enns GM, Packman W. The adolescent with an inborn error of metabolism: medical issues and transition to adulthood. Adolesc Med. 2002;13(2):315-29.

2. Lee PJ. Growing older: the adult metabolic clinic. J Inherit Metab Dis. 2002;25(3):252-60. https://doi.org/10.1023/a:1015602601091.

3. WHO. Medical eligibility criteria for contraceptive use Fifth edition 2015 Executive summary. Who. Published online 2015.

4. ACOG Practice Bulletin No. 206. Use of hormonal contraception in women with coexisting medical conditions. Obstet Gynecol. 2019;133(2):e128-50. https://doi.org/10.1097/AOG.0000000000003072.
5. Morris AAM, Kožich V, Santra S, et al. Guidelines for the diagnosis and management of cystathionine beta-synthase deficiency. J Inherit Metab Dis. 2017;40(1):49-74. https://doi.org/10.1007/s10545-016-9979-0.

6. Mairovitz V, Labrune P, Fernandez H, Audibert F, Frydman R. Contraception and pregnancy in women affected by glycogen storage diseases. Eur J Pediatr. 2002;161(Suppl):S97-101. https://doi.org/10.1007/ s00431-002-1013-X.

7. Sechi A, Deroma L, Lapolla A, et al. Fertility and pregnancy in women affected by glycogen storage disease type I, results of a multicenter Italian study. J Inherit Metab Dis. 2013;36(1):83-9. https://doi.org/10.1007/ s10545-012-9490-1.

8. van Wegberg AMJ, MacDonald A, Ahring K, et al. The complete European guidelines on phenylketonuria: diagnosis and treatment. Orphanet J Rare Dis. 2017;12(1):162. https://doi.org/10.1186/s13023-017-0685-2.

9. McCully KS. Homocystine, atherosclerosis and thrombosis: implications for oral contraceptive users. Am J Clin Nutr. 1975;28(5):542-9. https://doi. org/10.1093/ajcn/28.5.542.

10. Calderaro J, Labrune P, Morcrette G, et al. Molecular characterization of hepatocellular adenomas developed in patients with glycogen storage disease type I. J Hepatol. 2013;58(2):350-7. https://doi.org/10.1016/j.jhep. 2012.09.030.

11. Kishnani PS, Austin SL, Abdenur JE, et al. Diagnosis and management of glycogen storage disease type I: a practice guideline of the American College of Medical Genetics and Genomics. Genet Med. 2014;16(11): e1. https://doi.org/10.1038/gim.2014.128.

12. Balla S, Ekpo EP, Wilemon KA, Knowles JW, Rodriguez F. Women living with familial hypercholesterolemia: challenges and considerations surrounding their care. Curr Atheroscler Rep. 2020;22(10):60. https://doi.org/ 10.1007/s11883-020-00881-5.

13. Welling L, Bernstein LE, Berry GT, et al. International clinical guideline for the management of classical galactosemia: diagnosis, treatment, and follow-up. J Inherit Metab Dis. 2017;40(2):171-6. https://doi.org/10.1007/ s10545-016-9990-5.

14. Baumgartner MR, Hörster F, Dionisi-Vici C, et al. Proposed guidelines for the diagnosis and management of methylmalonic and propionic acidemia. Orphanet J Rare Dis. 2014;9:130. https://doi.org/10.1186/ s13023-014-0130-8

15. American Academy of Pediatrics. Maternal phenylketonuria. Pediatrics. 2001;107(2):427-8. https://doi.org/10.1542/peds.107.2.427.

16. Simoni MK, Mu L, Collins SC. Women's career priority is associated with attitudes towards family planning and ethical acceptance of reproductive technologies. Hum Reprod. 2017;32(10):2069-75. https://doi.org/10. 1093/humrep/dex275.

17. Matin BK, Williamson HJ, Karyani AK, Rezaei S, Soofi M, Soltani S. Barriers in access to healthcare for women with disabilities: a systematic review in qualitative studies. BMC Womens Health. 2021;21(1):44. https://doi.org/ 10.1186/s12905-021-01189-5.

18. Gleit R, Freed G, Fredericks EM. Transition planning: teaching sexual selfmanagement. Contemp Pediatr. 2014;31(4):16-22.

19. DeNoble AE, Hall KS, Xu X, Zochowski MK, PiehI K, Dalton VK. Receipt of prescription contraception by commercially insured women with chronic medical conditions. Obstet Gynecol. 2014;123(6):1213-20. https://doi. org/10.1097/aog.0000000000000279.

20. Phillips-Bell GS, Sappenfield W, Robbins CL, Hernandez L. Chronic diseases and use of contraception among women at risk of unintended pregnancy. J Womens Health (Larchmt). 2016;25(12):1262-9. https://doi. org/10.1089/jwh.2015.5576.

21. Louis-Jacques J, Samples C. Caring for teens with chronic illness: risky business? Curr Opin Pediatr. 2011;23(4):367-72. https://doi.org/10.1097/ MOP.0b013e3283481101.

22. No Title. Accessed 2 Aug 2021. https://www.ipledgeprogram.com/iPled geUl/home.u.

23. Den Heijer M, Lewington S, Clarke R. Homocysteine, MTHFR and risk of venous thrombosis: a meta-analysis of published epidemiological studies. J Thromb Haemost. 2005;3(2):292-9. https://doi.org/10.1111/j.1538-7836. 2005.01141.x.

24. Domagala TB, Adamek L, Nizankowska E, Sanak M, Szczeklik A. Mutations C677T and A1298C of the 5,10-methylenetetrahydrofolate reductase gene and fasting plasma homocysteine levels are not associated with the increased risk of venous thromboembolic disease. Blood Coagul 
Fibrinolysis Int J Haemost Thromb. 2002;13(5):423-31. https://doi.org/10. 1097/00001721-200207000-00007.

25. Krajewski C, Sucato G. Reproductive health care after transplantation. Best Pract Res Clin Obstet Gynaecol. 2014;28(8):1222-34. https://doi.org/ 10.1016/j.bpobgyn.2014.09.002.

26. Browne $H$, Manipalviratn $S$, Armstrong A. Using an intrauterine device in immunocompromised women. Obstet Gynecol. 2008;112(3):667-9. https://doi.org/10.1097/AOG.0b013e318183464e.

27. Boles RG, Stone ML. A patient with arginase deficiency and episodic hyperammonemia successfully treated with menses cessation. Mol Genet Metab. 2006;89(4):390-1. https://doi.org/10.1016/j.ymgme.2006. 07.012 .

28. Grody WW, Chang RJ, Panagiotis NM, Matz D, Cederbaum SD. Menstrual cycle and gonadal steroid effects on symptomatic hyperammonaemia of urea-cycle-based and idiopathic aetiologies. J Inherit Metab Dis. 1994;17(5):566-74. https://doi.org/10.1007/BF00711592.

29. Wakutani Y, Nakayasu H, Takeshima T, et al. A case of late-onset carbamoyl phosphate synthetase I deficiency, presenting periodic psychotic episodes coinciding with menstrual periods. Rinsho Shinkeigaku. 2001:41(11):780-5.

30. Bianconi SE, Cross JL, Wassif CA, Porter FD. Pathogenesis, epidemiology, diagnosis and clinical aspects of Smith-Lemli-Opitz syndrome. Expert Opin orphan drugs. 2015;3(3):267-80. https://doi.org/10.1517/21678707. 2015.1014472.

31. Perlroth MG, Marver HS, Tschudy DP. Oral contraceptive agents and the management of acute intermittent porphyria. JAMA. 1965:194(10):1037-42

32. Rowlands S, Amy J-J. Sterilization of those with intellectual disability: evolution from non-consensual interventions to strict safeguards. J Intellect Disabil. 2019;23(2):233-49. https://doi.org/10.1177/1744629517747162.

33. Li H, Mitra M, Wu JP, Parish SL, Valentine A, Dembo RS. Female sterilization and cognitive disability in the United States, 2011-2015. Obstet Gynecol. 2018;132(3):559-64. https://doi.org/10.1097/AOG.0000000000002778.

34. van Erven B, Berry GT, Cassiman D, et al. Fertility in adult women with classic galactosemia and primary ovarian insufficiency. Fertil Steril. 2017;108(1):168-74. https://doi.org/10.1016/j.fertnstert.2017.05.013.

35. Granovsky-Grisaru S, Aboulafia Y, Diamant YZ, Horowitz M, Abrahamov A, Zimran A. Gynecologic and obstetric aspects of Gaucher's disease: a survey of 53 patients. Am J Obstet Gynecol. 1995;172(4 Pt 1):1284-90. https://doi.org/10.1016/0002-9378(95)91494-3.

36. Zimran A, Morris E, Mengel E, et al. The female Gaucher patient: the impact of enzyme replacement therapy around key reproductive events (menstruation, pregnancy and menopause). Blood Cells Mol Dis. 2009;43(3):264-88. https://doi.org/10.1016/j.bcmd.2009.04.003.

37. Cox TM, Aerts JMFG, Belmatoug N, et al. Management of non-neuronopathic Gaucher disease with special reference to pregnancy, splenectomy, bisphosphonate therapy, use of biomarkers and bone disease monitoring. J Inherit Metab Dis. 2008;31(3):319-36. https://doi.org/10. 1007/s10545-008-0779-z.

38. Kishnani PS, Austin SL, Arn P, et al. Glycogen storage disease type III diagnosis and management guidelines. Genet Med. 2010;12(7):446-63. https://doi.org/10.1097/GIM.0b013e3181e655b6.

39. Watts GF, Gidding S, Wierzbicki AS, et al. Integrated guidance on the care of familial hypercholesterolemia from the International FH Foundation. J Clin Lipidol. 2014;8(2):148-72. https://doi.org/10.1016/j.jacl.2014.01.002.

40. Kalinowski AH, Quint EH, Weyand AC. The perfect balance? Managing heavy menstrual bleeding and dysmenorrhea in a patient with hereditary hemochromatosis and von Willebrand disease. J Pediatr Adolesc Gynecol. 2021;34(1):74-6. https://doi.org/10.1016/j.jpag.2020.10.003.

41. Wraith JE, Baumgartner MR, Bembi B, et al. Recommendations on the diagnosis and management of Niemann-Pick disease type C. Mol Genet Metab. 2009;98(1-2):152-65. https://doi.org/10.1016/j.ymgme.2009.06. 008.

42. van Spronsen FJ, van Wegberg AM, Ahring K, et al. Key European guidelines for the diagnosis and management of patients with phenylketonuria. Lancet Diabetes Endocrinol. 2017;5(9):743-56. https://doi.org/10. 1016/S2213-8587(16)30320-5.

43. Camp KM, Parisi MA, Acosta PB, et al. Phenylketonuria Scientific Review Conference: state of the science and future research needs. Mol Genet Metab. 2014;112(2):87-122. https://doi.org/10.1016/j.ymgme.2014.02. 013.
44. Connolly TJ, Zuckerman AL. Contraception in the patient with liver disease. Semin Perinatol. 1998;22(2):178-82. https://doi.org/10.1016/ s0146-0005(98)80050-5.

45. Haimov-Kochman R, Ackerman Z, Anteby EY. The contraceptive choice for a Wilson's disease patient with chronic liver disease. Contraception. 1997;56(4):241-4. https://doi.org/10.1016/s0010-7824(97)00141-8.

46. EASL Clinical Practice Guidelines. Wilson's disease. J Hepatol. 2012;56(3):671-85. https://doi.org/10.1016/j.jhep.2011.11.007.

47. Kathawala M, Hirschfield GM. Insights into the management of Wilson's disease. Therap Adv Gastroenterol. 2017;10(11):889-905. https://doi.org/ 10.1177/1756283X17731520.

48. Patil M, Sheth KA, Krishnamurthy AC, Devarbhavi H. A review and current perspective on Wilson disease. J Clin Exp Hepatol. 2013;3(4):321-36. https://doi.org/10.1016/j.jceh.2013.06.002.

49. Nash AL, Cornish EJ, Hain R. Metabolic effects of oral contraceptives containing 30 micrograms and 50 micrograms of oestrogen. Med J Aust. 1979;2(6):277-81.

50. Ruoppolo M, Campesi I, Scolamiero E, et al. Serum metabolomic profiles suggest influence of sex and oral contraceptive use. Am J Transl Res. 2014;6(5):614-24.

51. Godsland IF, Crook D, Simpson R, et al. The effects of different formulations of oral contraceptive agents on lipid and carbohydrate metabolism. N Engl J Med. 1990;323(20):1375-81. https://doi.org/10.1056/NEJM1 99011153232003

52. Barros RPDA, Morani A, Moriscot A, Machado UF. Insulin resistance of pregnancy involves estrogen-induced repression of muscle GLUT4. Mol Cell Endocrinol. 2008;295(1-2):24-31. https://doi.org/10.1016/j.mce.2008. 07.008.

53. Anderson KE, Bodansky O, Kappas A. Effects of oral contraceptives on vitamin metabolism. Adv Clin Chem. 1976;18:247-87. https://doi.org/10. 1016/s0065-2423(08)60300-5

54. Webb JL. Nutritional effects of oral contraceptive use: a review. J Reprod Med. 1980;25(4):150-6.

55. Rose DP. The interactions between vitamin $\mathrm{B} 6$ and hormones. Vitam Horm. 1978;36:53-99. https://doi.org/10.1016/s0083-6729(08)60982-6.

56. Butler JD, Blanchette-Mackie J, Goldin E, et al. Progesterone blocks cholesterol translocation from lysosomes. J Biol Chem 1992:267(33):23797-805.

57. Wang $Q$, Würtz $P$, Auro K, et al. Effects of hormonal contraception on systemic metabolism: cross-sectional and longitudinal evidence. Int J Epidemiol. 2016:45(5):1445-57. https://doi.org/10.1093/ije/dyw147.

58. Bach AC, Schirardin H, Storck D. Plasma carnitine in women. Effects of the menstrual cycle and of oral contraceptives. Arch Int Physiol Biochim. 1983;91(4):333-8. https://doi.org/10.3109/13813458309067978.

59. Roberts EA, Schilsky ML. Diagnosis and treatment of Wilson disease: an update. Hepatology. 2008;47(6):2089-111. https://doi.org/10.1002/hep. 22261.

\section{Publisher's Note}

Springer Nature remains neutral with regard to jurisdictional claims in published maps and institutional affiliations.

Ready to submit your research? Choose BMC and benefit from:

- fast, convenient online submission

- thorough peer review by experienced researchers in your field

- rapid publication on acceptance

- support for research data, including large and complex data types

- gold Open Access which fosters wider collaboration and increased citations

- maximum visibility for your research: over $100 \mathrm{M}$ website views per year

At BMC, research is always in progress.

Learn more biomedcentral.com/submissions 